\title{
Sport, Social Division and Social Inequality
}

\author{
Grant JARVIE
}

\begin{abstract}
$\mathrm{T}$ This article examines different forms of social division and social inequality which impact upon contemporary sport. The research draws upon and contributes to contemporary sports participation data in one country. It also draws upon some examples of research from countries other than UK in order to provide a broader international perspective. It examines new forms of inequality and some of the ways in which sport has helped to support social change. It suggests that future researcher examining the relationship between sport and social inequality might think of this in at least three ways (i) inequality of condition; (ii) inequality of opportunity and (iii) inequality of capability. The research supports the argument that sport has a part to play in improving the life chances. The research provides a valuable comparative example from which to develop further comparative research in this area.
\end{abstract}

Keywords: sport, social inequality, social class, gender, ethnicity, social change, life chances

\section{Introduction}

Whenever one is pondering the dynamics of social divisions or forms of inequality in sport it is always useful to consider who is sport and how have social structures provided both continuity and change in sport? Undoubtedly a global gap continues to define to-days world with more than 1.2 billion people living on less than $\$ 1$ a day. $46 \%$ per cent of the world's population lives on less that $\$ 2$ a day. The gap in social inequality is both between countries as well as within countries. To put this in some comparative context, for the season 2003-4 the wage and transfer bill of the four English football divisions stood at $f_{1}, 049$ billion, a figure which eclipses the gross domestic product of some small African nations such as Lesotho and Mauritania, and could wipe out most of the debt of many countries both within and outside of Africa. The transfer of sporting 
capital both in terms of human and physical forms helps to sustain social divisions between different parts of the world as well as promote the illusion or myth of social inclusion - a much over used term. Sport, social divisions and social inequality while recognizing traditional forms of $20^{\text {th }}$ century forms of inequality in sport considers the way in which sport today both reinforces forms of social inequality while providing a resource of hope for some people.

This article is structured around four themes (i) social divisions and the new tribes which introduces new forms of inequality in the UK based upon people's attitudes to equality and fairness; (ii) sport and social class which eschews traditional class barriers in sport while acknowledging campaigns for changesome of which are outside of the UK; (iii) the role of gender and sporting heroines in challenging traditional forms of authority and (iv) the impact of the Obama phenomenon in the USA and in particular the part played by sport in providing a contribution to what Obama refers to as the audacity of hope. These four themes are not exhaustive of the all different forms of social division that permeate sport today they do nonetheless reflect upon the ways in which sport - despite exaggerated claims of social inclusion or exclusion in some countries continues to provide many possibilities within certain limits. The research for this article is derived from an analysis of UK participation data which has been placed in a broader context as a basis for commenting upon sport in UK society.

\section{Social Divisions and the New Tribes}

Socio-economic systems differ in the degree to which they constrain the rights and powers of different groups of people in different countries. The class structure in the United Kingdom is not the same as the class structure in America or Asia. Patterns of interaction between different social divisions at times disproportionately marginalise segments of the population. In the United States of America while the class structure at the beginning of the $21^{\text {st }}$ century includes an extremely rich capitalist class and corporate managerial class, living at extraordinarily high consumption standards, with fluctuating constraints on their exercise of economic power following the emergence of recession in 2008 , it also reflects a pattern of interaction between race and class in which the working poor and the marginalised population are disproportionately made up of racial minorities.

The potential coherence of social divisions lies in the notions of hierarchy, social inequality and social injustice that permeate sport. Complex social divisions are not just about the reality of everyday sport but rather they reinforce the fact that whatever categories are used unequal access to sport tends to continually impinge upon the same categories of people. The gap between rich and poor 
remains a significant gap. Any discussion of sport and social inequality that relates solely to class, ethnicity gender, or any singular category fails to raise issues of poverty, capability, injustice and the precise nature of the limits and possibilities that are open to people. No one single story can address every form of oppression, identity or political aspiration but sport in the world today has to be much more sensitive to the shear diversity of the multiple axes of power and inequality.

New social divisions are emerging all the time but in the Britain of the $21^{\text {st }}$ century new attitudes towards inequality and fairness might suggest that the orthodox traditional forms of inequality are themselves not as important as they were in the $20^{\text {th }}$ century. New social divisions are emerging. Researchers in the UK have begun to ask new questions about social inequality (Hampson and Olchawski, 2009). Four fairly equal clusters of opinions and groups seem to be emerging out of this recent research. The traditional egalitarians $(22 \%)$ support measures to tackle inequality at both the top and the bottom. They tend to be older and more heavily weighted towards Labour with 55\% in socio-economic group C2DE. The traditional free marketers $(20 \%)$ oppose measures to tackle inequality at both the top and the bottom. They are overwhelmingly in socioeconomic groups $\mathrm{ABC1}(70 \%)$ and are much more heavily weighted towards the Conservatives than the country as a whole. The angry middle $(26 \%)$ support measures to tackle inequality at the top, while opposing measures to tackle inequality at the bottom. They are slightly more weighted towards the Conservatives than the country as a whole and $53 \%$ are ABC1. Finally a fourth grouping, the post ideological liberals (52\%) support certain measures to tackle inequality at the top (although they have more positive attitudes towards those at the top than Traditional Egalitarians) without having negative attitudes towards those in poverty or being opposed to tackling inequality at the bottom (unlike the traditional free marketers and the angry middle). Most of the new tribes are strongly attracted to a social vision framed around improving the quality of life for all.

Sport and Social Class. Sport has long been viewed as a graphic symbol of meritocracy despite the fact that sociologists and others have been questioning the substantive basis for such a claim for more than quarter of a century. Thus the popular image of sport as an unquestioned democracy of ability and practice is somewhat over-exaggerated if not mythical. Generally speaking, the term democratisation tends to imply a widening degree of opportunity or a diminishing degree of separatism in varying forms of sports involvement. The term has been used to describe the process whereby employees or clients have more control over sporting decisions and sporting bodies. The expansion of opportunities in sport has been used at one level to argue that sport, at least, in the West has become more open and yet the reality in Britain is that the extremes 
of privilege and poverty remain sharply drawn. An emphasis on social class cannot explain all aspects of the development of British sport but there is good reason for believing that sport and social class have been mutually reinforcing categories in British society for a long time.

It is important to ask who plays sport. The figures presented below relate to sports participation and social class in one country towards the end of the $20^{\text {th }}$ century (Jarvie, 2006; Sportscotland, 2010): (i) that the most popular participatory sports amongst class category $\mathrm{AB}$ were curling, cricket skiing, sailing and tennis; (ii) that the most popular sports amongst DE category included snooker/ billiards/pool, ice-skating/ice-hockey, fishing/angling, dancing and walking; (iii) that sports participation in all sports is most popular amongst social class C1 (30\%); followed by DE (26\%), $\mathrm{AB}(23 \%)$ and C2 (21\%); (iv) that with reference to particular sports; golf participation by social class is made up of $\mathrm{AB}(33 \%)$, C1 $(32 \%), \mathrm{C} 2(20 \%)$ and DE (15\%); football participation by social class is made up of $\mathrm{AB}(19 \%), \mathrm{C} 1(32 \%), \mathrm{C} 2(25 \%)$ and $\mathrm{DE}(24 \%)$; bowls participation by social class is made up of $\mathrm{AB}(22 \%), \mathrm{C} 1(32 \%), \mathrm{C} 2(21 \%)$ and DE $(25 \%)$; and athletics participation by social class is made up of AB (24\%), C1 (30\%), C2 (24\%) and DE $(16 \%)$; (v) that sports such as squash would appear to be extremely elitist in terms of participation $\mathrm{AB}(39 \%)$ and $\mathrm{DE}(5 \%)$ and (vi) that sports such as walking $\mathrm{AB}(24 \%), \mathrm{C} 1(30 \%), \mathrm{C} 2(20 \%)$ and $\mathrm{DE}(26 \%)$, swimming $\mathrm{AB}(26 \%)$, C1 $(31 \%), C 2(21 \%)$ and DE (22\%) and cycling AB (27\%), C1 $(32 \%), C 2(20 \%)$ and DE $(21 \%)$ are fairly democratic in terms of participation.

Such evidence is never complete but it addresses the question who is sport rather than what is sport. Arguments about sport and social class have tended to suggest (i) that it is possible to identify a leisure class that is involved in the conspicuous consumption of sport (ii) that sport helps to sustain and reproduce status, prestige and power; (iii) that the struggle for sport has been influenced by social class (iv) that the practice of sport is socially stratified and differentiated by social class; (v) that sport within and between social classes acts as a hallmark of distinction; (vi) that sport is intimately associated with classes that exist on the basis of the differential distribution of wealth, power and other characteristics; (vii) that sport contributes to a distinct way of life associated with certain class categories; (viii) that social class has contributed to the discourse of colonial sport within and between certain former colonies and nations and (ix) that class networks continue to afford capacity and opportunity for some. Sport and social class is not dead but perhaps the monolithic social imagery of class as a driver of change is not as forceful in the $21^{\text {st }}$ century as it was in the $20^{\text {th }}$ century.

There are times in human history when liberalisation in the direction of harmless fun can be absorbed in an upward movement of an optimistic and 
expansive society. For many in Britain much of the second half of the $20^{\text {th }}$ century the answer lay in labour with a small and large L, in work itself, in the organisation of people who did the work so that their rewards began to match the value of their efforts and in the progress of a political party that historically represented the working class, the unrepresented and those in poverty. This traditional synergy as declined. For many the relationship between sport, class and the lottery in the $21^{\text {st }}$ century is just another symptom of decline, a change of focus, a feeling of uncertainty and insecurity in a world in which collectivism and solidarity in many instances has been replaced by irreverence and individualism. A nation of subjects who historically felt that they had some control over their fate through elections, security of pensions, representation and the communities where they lived has been replaced by a loose collection of individuals living in a global world of uncertainty where even the winnings from the sports lottery are distributed elsewhere. A nation of ricocheting pinballs in some vast global bagatelle machine in which the anonymous financial bankers of the universe pulled the levers which gave rise to the beginning of an economic recession in 2008 .

The national lottery has become an icon of uncertainty, individualism, false hope which even in sporting terms has failed to supply the financial security and provision that was promised. The number of good causes funded through lottery provision has meant reduced funding for sport in many if not all parts of Britain. A Britain in which some people are doing rather well for themselves while other remain marginalised, disadvantaged within sport and in terms of the opportunities for physical activity. A 30/30/40 society, in which the privileged $40 \%$ remain comfortable, can access private sporting clubs and have sustained their power in the market place. A further 30\% which due to their changing relationship to the market place, insecurity of pension provision and an ageing society have become marginalised but also increasingly politically active as a result of the changes and a further 30\% who remain disadvantaged. In $200525 \%$ of children living in Scotland under the age of sixteen continue to live in poverty (The Herald, 31 March 2005, p. 2). Thirteen million people live in poverty in the UK including one in three children (Hampson and Olchawski, 2009). It has been suggested in the Britain of the $21^{\text {st }}$ century that while the lottery draws more of a working class support in terms of distribution, the distribution of prize-money is disproportionately biased towards middle and upper class sporting tastes. The poor have always had to live with insecurity and uncertainty and while sport used to be a traditional avenue of social mobility even this has been increasingly left to chance.

Yet the relationship between sport, social class and campaigns for social change remains a relevant challenge to equitable, neoliberal notions global sport. It would be misleading to suggest that as a major driver of social change social 
class is no longer relevant to bringing about transformation in sport. It is evident even in sport that social class cannot be viewed as a static entity. It has a life form that changes as result of social and historical processes and consequently finds different forms of expression in political movements that endorse forms of social change in and through sport. Many forms of class conflict have been deflected into anti-immigrant and anti-Muslim campaigns. Many forms of traditional urban and rural forms of social class activism have re-emerged and confronted each other over the fight to ban foxhunting in Scotland and England. The International Labour Organisation in conjunction with FIFA and UNICEF launched the Red Card to Child Labour campaign in conjunction with the 2002 African Nations Cup while Fabians in the $21^{\text {st }}$ century have campaigned not only against corruption in world sport but also the need to develop a more progressive politics of sport that promotes co-operation, mutuality and a fostering of trust between different groups who share such concerns (Katwala, 2004). The traditional working class game of football struggles through partially state sponsored movements such as supporter's trusts to gain or cease an increased say in the running of clubs. The very cost of viewing elite football is in itself a barrier to many people. The average price of a season ticket for Manchester United Football Club in season 2009-10 was $£ 730$.

In other countries where football is deemed to be important, such as Brazil, governments have taken alternative steps to bring about social change through football. In 2002 Luiz Inacio Lula de Silva was elected President of Brazil. The content of the administrations policies were also influenced by football in that the first two laws that the President signed in May 2002 concerned football. Football in Brazil was one of the key battlegrounds upon which the battle to make the country a fairer place was being fought. The sport had been run by a network of unaccountable largely corrupt figures known as carrolas or 'top hats' who had become obscenely wealthy while the domestic football scene remained broke and demoralised (Bellos, 2003: 32). The public plundering of football was viewed by the President as a continual reminder of the previous administration's failure to stamp out corruption in areas of public life. Lula in an attempt to force the football authorities to become transparent ratified a Law of Moralisation in sport that enforced transparency in club administration (Bellos, 2003:32). On the same day he sanctioned a more ambitious and wide ranging law the 'Fans Statute', a bill of rights for the football fan.

Social class continues to impact upon campaigns for social change in sport and yet this particular expression of social class activism has combined diverse social and political protests with different forms of ideological awareness. While one of the elements of the erosion of deference has been the creation of new forms of rebellious collectivism, the motor of sport and social class as an engine 
of social change is not dead. It may have shifted geographically. Many of the progressive successes and challenges in and for world sport continue to be linked to traditional areas of concern such as poverty and labour. Classical irreverent collectivism linked to sport and working class movements may have passed its historical high point and maybe progressively weakening and yet it would be foolish and unscientific not to acknowledge the continuing significance of social class politics in bringing about social change in sport. There maybe less class but their is certainly more irreverence which may also express itself in repulsive forms in xenophobic, violence or crime. It may also still reassert itself in struggles over the ownership and direction of football clubs in the UK.

The very poor of course are not in the main seats and as John Underwood (2009) writing in the New York Times has explained:

"The great damage done by this new elitism is that even the cheapest seats in almost every big-league facility are now priced out of reach of a large segment of the population. Those who are most critically in need of affordable entertainment, the underclass (and even the lower middle class), have been effectively shut out. And this is especially hateful because spectator sport by its very nature has been the great escape for men and women who have worked all day for little pay and traditionally have provided the biggest number of a sports core support. As it now stands, they are as good as disenfranchised- a vast number of the taxpaying public who will never set foot inside these stadiums and arena".

Sporting Heroines, Feminism and the Post Neo-Liberal era. It is often suggested that the most widely help view of second-wave feminism is the sharp contrast between the relative success in transforming cultures and the relative failure in transforming institutions. This assessment is double edged given the for on the one hand feminist ideals of gender inequality now sit squarely in the social mainstream but have yet to be fully realized in practice. Thus feminist critiques of sexual harassment, sexual trafficking and unequal pay are widely espoused to-day but the level of sea change in such attitudes has no means eliminated such practices. Thus issues of gender justice in the present period just like other forms of social division need to be concerned with issues of redistribution, recognition as well as representation. Global capitalism is itself at a crossroads given the global financial crisis and the election of Barack Obama may signal a further challenge to the neo-liberal project and it remains to be seen as to whether the optimism of a further period of transformation is to be realised. As such there is a need to continue to link hopes for change for women in and through sport with a vision of hope for a better society or worlds of sport in a Post Neo-Liberal era. 
The very same question about who is sport is just as important in the context of a discussion of sporting heroines. The figures presented below relate to sports participation by women in one country towards the end of the 20th century (Jarvie, 2006; Sportscotland 2010): (i) that the most popular participatory sports amongst women are aerobics $(75 \%)$, dancing $(74 \%)$, swimming $(60 \%)$, yoga $(87 \%)$ and horse-riding $(75 \%)$ whilst the least popular sports in terms of participation are football $(7 \%)$, fishing/angling $(8 \%)$, rugby $(8 \%)$, golf $(12 \%)$ and squash (15\%); (ii) that the most popular participatory sports amongst men are football $(93 \%)$, rugby $(92 \%)$, golf $(88 \%)$, fishing/angling $(92 \%)$ and squash $(84 \%)$ whilst the least popular sports in terms of participation are yoga $(13 \%)$, aerobics $(25 \%)$, dancing $(26 \%)$, horse-riding $(25 \%)$, and gymnastics $(29 \%)$; (iii) that women's participation in sports in sport in this country is dominated by four activities while men participate in a much wider range of sports with 12 sports having participation rates of above 5\% compared with six such sports for women; (iv) that sports that have the smallest gender gap in terms of participation include Curling $(51 \% \mathrm{M}$ and $48 \% \mathrm{~F}=3 \%$ difference), Badminton $(52 \% \mathrm{M}$ and $48 \% \mathrm{~F}=4 \%$ difference), Tenpin bowling $(53 \% \mathrm{M}$ and $47 \% \mathrm{~F}=6 \%$ difference), Hockey and $(53 \% \mathrm{M}$ and $47 \% \mathrm{~F}=6 \%$ difference) and (v) that in terms of total sports participation a gender gap of $4 \%$ exists between men $(52 \%)$ and women $(48 \%)$.

Arguments about sport and women have suggested: (i) that different structures of masculinity and femininity have historically influenced the development of sport; (ii) that it is necessary to ask the question where are the women in sport in order to highlight issues of oppression, marginality and empowerment of women in sport; (iii) that gender is a fundamental category through which all aspects of life are organised and experienced including sport; (iv) that experiences of gender in sport need to be sensitive and aware of 'other' experiences of sporting struggle out with mainstream and or colonial gender relations; (v) that body culture and physicality are important facets of gender relations that also need to be explored and explained in terms of social division and social differences; (vi) that sport and gender relations have contributed to both reformist, emancipatory and evolutionary aspects of social change; and continuity and (vii) that sport and gender remains an important and insightful element of social division in its own right.

Key areas of social change fought for by women in and through sport continue to include the struggle for: (i) a more representative coverage for women within the Women's International Sports Movement; (ii) concerns over the existence and strategies aimed at the amelioration of sexual harassment in sport; (iii) raising awareness of women in sport across the world; (iv) improved conditions for women in sport; $(v)$ increased representation for women in sport 
both through the existing structures and new structures; (vi) women's health and well-being in all parts of the world; (vii) ensuring that the women executives in positions of power listen to and do not distance themselves from ordinary women who are the majority and (viii) acknowledge that the culture of movement is different for ordinary women in different parts of the world.

The Women's International Sports Movement has been but one an effective advocate for change in sport but also a successful conduit between sport and other organisations such as the United Nations. The reality of speaking as one voice maybe utopian but co-operative work between women in sport has meant that their is a greater potential or hope for the international voice of women in sport being heard within the mainstream of other international movements supporting and advocating for women in different parts of the world. The Women's International Sports Movement struggled with the question of representation but the future of a global sports feminism and the Women's International Sports Movement lies in the potential to unite women across social divisions and differences and as such the future remains international in focus and dependent upon effective coalitions both within sport and between sport and other forms of difference including generations of feminisms.

In 1792, more than two hundred years ago, commenting upon the vindication of the rights of women, Mary Wollstonecraft noted that it was justice and not charity that was wanting in the world at that time. Women and feminist movements have continually questioned male radical leadership of movements for liberation and equality in which traditional gender roles have remained unchanged. Overall feminism has been a movement of the Left, in the broadest sense, although more so in Western Europe and, in its own way, in the Third World - questioning the masculinist rule of capital as well as patriarchythan in the USA. Whether or not the contemporary women's movement or other forms of activism involving women's issues provides the prototypical alternative social movement is open to question but certainly struggles for women's sport have benefited from international support, collectivism and forms of solidarity. Struggles for women's sport and other forms of justice for women have been sensitive to other traditions of emancipatory internationalism and in this sense a similarity exists between labour and women's movements. One of the major reasons for the advances, policies and interventions won by women in sport has not only been the heightened sense of forms of common orientation but also the linkage of the women's movement to struggles for women in different parts of the world.

Furthermore as Fraser (2009:114) has recently pointed out the advantages of contemporary dangerous liaisons between feminism and neoliberalism based 
upon a mutual critique of traditional authority may also exist. Such authority as male dominated forms of sport is a longstanding target of feminist activism. However traditional authority also appears in some periods as an obstacle to capitalist expansion and therefore in this current moment the two critiques of traditional authority, one feminist and the other neo-liberal seems to converge. If the feminist critique of sport integrated in more balanced way issues of redistribution, recognition and the idea of justice then should it not be possible to reconnect such a feminist critique of sport and social inclusion under capitalism. The current ongoing recession and the impending transformation of the public realm provide the opportunity to re-direct sport in the direction of justice - and not only with regards to gender.

Sport and Racism in an Era of Audacity. Arguments about the relationship between sport, racism and ethnicity have tended to rely upon some of or all of the following arguments. That sport (i) is inherently conservative and helps to consolidate patriotism, nationalism and racism; (ii) has some inherent property that makes it a possible instrument of integration and harmonious ethnic and race relations; (iii) as a form of cultural politics has been central to processes of colonialism, imperialism and post-colonialism in different parts of the world; (iv) has contributed to unique political struggles which have involved black and ethnic political mobilization and the struggle for equality of and for black peoples and ethnic minority groups; (v) is an important facet of ethnic and racial identities; (vi) has produced stereotypes, prejudices and myths about ethnic minority groups which have contributed both to discrimination against and an under-representation of ethnic minority peoples within certain sports; (vii) that race and ethnicity are factors influencing choices that people make when they chose to join or not join certain sports clubs; (viii) needs to develop a more complex set of tools for understanding the limits and possibilities that influence sport, racism and ethnicity and in particular the way such categories historically articulate with other categories and social divisions.

In 2000 four broad generalisations were made about sports participation in England (Jarvie, 2006; UK Sport 2010). These included: (i) that Black African $(60 \%)$ and Black Other $(80 \%)$ men have higher participation rates than the national average for England (54\%); (ii) that Indian (47\%), Black Caribbean (45\%), Bangladeshi (46\%) and Pakistani (42\%) men are less likely to participate in sport than men in the population as a whole; (iii) that national participation rates for women $(39 \%)$ are matched or exceeded by women from Black Other (45\%), Other (41\%) and Chinese (39\% ethnic groups and (iv) that women who classify themselves as Black Caribbean (34\%), Black African (34\%), Indian $(31 \%)$, Pakistani $(21 \%)$ and Bangladeshi $(19 \%)$ have participation rates below the national average for all women. 
At the same time sport has also been explicitly been involved with campaigns, activism, policies and protests aimed at discrediting explicit racism and the power of colonialism. The struggle for sport has involved drawing attention to the fact that up until the sixties many black and other peoples of colour in the United States were still denied human and civil rights. The de-colonisation of Africa, the attempt to defeat institutional racism in the United States, the overthrow of apartheid in South Africa and the defeat of US imperialism in Cuba and Vietnam have all implicated sport as an area of activism if not policy intervention.

Some of the most prominent areas of legislation and injustice in sport have grown out of struggles over racism: (i) the period of apartheid sport in South Africa from 1948 to 1992 when specific racial legislation which separated the practice of sport by racial groupings gave rise to the international slogan 'You cannot have normal sport in an abnormal society'; (ii) the practice of colonialism in many parts of the world which formed the backcloth to sporting relations between many countries. During the 1960s and 1970s the cricket rivalry between England and the West Indies reflected racial tensions and racism rooted in years of colonial struggle. Terms such as White Wash and Black Wash were used to refer to English or West Indian victories while at the same time sport took on the mantle of symbolic colonial/ anti-colonial struggle both between the two teams but also in the selection of the West Indian team as is explained in CLR James 's (1963) classic period account of West Indian cricket; (iii) the popularity and world wide coverage of sport has meant that sport as vehicle for protest has been a successful medium for drawing attention to the treatment of Black-Americans as second class citizens in the United States of America and in American Sport as evidenced by the Black Power protests at the 1968 Mexico Olympic Games. The extent to which Aborigine's or Inuit peoples have also been marginalized in mainstream Australian or Canadian sport has also been a target for sporting activists. For example much of the coverage of the 2000 Sydney Olympic Games revolved around the performances of the 400m Olympic Gold Medallist Cathy Freeman and the plight of Aborigine's living in contemporary Australia; and (iv) legislation such as the Race Relations Acts of 1976 and 2004 in Britain which provides the legal machinery of the law to investigate and act against racism in all walks of life in Britain, including sport.

Equally there are important historical moments that can symbolise a prejudice, a protest, an ideology or a breaking down of barriers. Sport has both been racist but also provided some of the most poignant anti-racist moments. In 1881 Andrew Watson became the first black player to play for Scotland at football/soccer. In August 1936 Jesse Owens won an unprecedented four gold medals at the Nazi Olympic Games in Berlin. Two years later Joe Louis crushed 
Max Smelling to signal the end of a period of white supremacy in boxing. In 1967 Muhammed Ali, the World Heavyweight boxing Champion condemned the war in Vietnam arguing that he did not have any quarrel with the Vietcong. One year later in October 1968 American black athletes protested from the Olympic medal rostrum against the treatment of black people in America and elsewhere, notably South Africa. Evonne Cawley (Goolagong) became the first aboriginal Australian to play in a Wimbledon Tennis final in 1971, two years before Arthur Ashe became the fist Black American to win the Wimbledon Men's Tennis Championship in 1973. In 1995 Nelson Mandela following South Africa's victory in the Rugby World Cup talked of Sport as force that could mobilise the sentiments of a people in a way that nothing else could. Three years later when Zinedine Zidan lifted the Football World Cup for France the French President talked of the French Football team as being symbolic of the New Multi-Racial integrated France. In 2001 arguably the world's greatest footballer Pele endorsed a world wide anti-racist campaign in football with the words that racism is cowardice that comes from fear, a fear of difference. In February 2002 Vonetta Flowers became the first African American to win a gold medal at the Winter Olympic Games. In 2006 England bowler Monty Panesar became the first Sikh to represent any nation except India in Test Match Cricket (Armstrong, 2008).

In 1997, when Tiger Woods won the Masters and donned the green jacket that accompanied the winning of the coveted title, golf became thrilling to watch for an entirely new audience. On the hallowed putting greens of Augusta, where Woods would not have been allowed membership a few years earlier, history had been made. Social change through sport occurred and at the time America did not have the language to deal with the change. Not since Lee Elder squared off against Jack Nicklaus in a sudden death playoff at the American Golf Classic in 1968 had a black golfer gained so much televised attention (Bass, 2002). The sports press cast the feat of Woods as breaking a modern colour line, yet no one including Woods himself could fully describe exactly what colour line had been broken. The press conveyed his parental heritage as variously African American, Asian and Native American, overwhelmingly others portrayed Woods as a black athlete, a golfer who had brought about change in the same way attributed to the likes of Jesse Owens, Tommie Smith, John Carlos Muhammad Ali, Tydie Pickett, Louise Stokes, Vonetta Flowers and Alice Cochrane. Woods himself did not consider himself in such terms but embraced a more nuanced racial heritage more representative of the melting pot imagery associated with American history and a determining demographic factor of so-called Generation X (Bass, 2002:xvi).

This article is being written as the financial crisis of 2008-10 continues to unfold and the age of extremes would appear to have been replaced by the age of austerity tempered the audacity of hope reflected in the aspirations of 
a new American president - President Obama. One the eve of the election for the new President of the United States of America (USA) both Barack Obama and John McCain were interviewed on the half-time show of Monday Night Football. Asked the same questions, they differed significantly on only one: if you could change one thing about American sports what would it be? McCain offered something worthy about sorting out the steroid problem while Obama wanted a college football play-off. Obama is not only the first black President of the USA but the first President to identify himself primarily as a basketball fan. The perception of been seen to be a sports fan associated with certain sports is not new Reagan played football at college, Bushes senior and junior were both baseball men, Clinton did play basketball at Oxford but Obama's basketball credentials are good. It has been widely reported that he shook off Election Day nerves playing basketball. In Dreams of my Father, Obama writes 'that I was trying to raise myself to being a black man in America and, beyond the given of my appearance, no one around me seemed to know what that meant' (Obama, 2008:9). One thing it means is basketball, the dominance of African Americans on the basketball court is so well established and documented it is hardly commented up anymore. In 2009 the Washington Wizards Obama's new local team, had 15 players on the roster, 13 of them African American. Obama's presidency will coincide with an aggressive expansion by the National Basketball Association (NBA) and it hopes to establish a club in Europe within this time. One of the problems it faces is the NBA draft laws which are the American method of dividing up young talent which might just be too socialist for European employment law (Markovits, 2003:28).

\section{Concluding Remarks}

Social inequalities traditionally referred to the differences in people's share of and access to resources and opportunities. The term social inequality in relation to sport and other areas can be thought of in at least three senses (i) inequality of condition which may refer to variations in factors such as income, education, occupation or the amount of time to spend on sport, exercise and recreation; (ii) inequality of opportunity which focuses more on the individual and is concerned with the degree of freedoms that people have in moving within and between the restrictions set by a reward structure and (iii) inequality of capability which refers to the differences that individuals or groups may have as a result of inequalities in power and capability. A redistribution of income resources clearly affects different social divisions and people living in different countries but it is what people do with this resource that is important. For social thinkers such as Amartya Sen (2009) the issue of inequality of capabilities - in other words what people do with resources - literacy, nutrition, access to sport and the power to participate in the social life of the community that is also crucial. 
Improving life chances requires a co-ordinated effort and as such any contribution that sport can make must also build upon a wider coalition of sustained support for social and progressive policies. The life chances approach to narrowing the gap between rich and poor has a key role to play in producing social change. It requires harnessing a strong political narrative and action plan that fits with many people's intuitive understanding that life should not be determined by socio-economic position and that people do have choices. The idea of justice exposes the idea that to be genuinely free you have to have a capability set. What Sen (2009) argued was that the market economy is not a free-standing institution, nor a self-regulating one. You need support from other institutions. You need other resources of hope. You need supervision from the state, you need supplementation by the state and society to take care of poverty, ill-health, illiteracy, and educational achievement and opportunity.

Finally, while it is important to explain and understand economic, social, and comparative explanations of what sport can do for society, the more important intellectual and practical questions often emanate from questions relating to social change. Historically the potential of sport lies not with the values promoted by global sport or particular forms of capitalism for as we have shown in this chapter these are invariably unjust and uneven. The possibilities that exist within sport are those that can help with radically different views of the world perhaps based upon opportunities to foster trust, obligations, redistribution and respect for sport in a more socially orientated humane world.

\section{References}

Armstrong, S. (2008). Is British Sport still racist?' New Statesman. 18 November: 32-34.

Bass, A. (2002). The Triumph but the Struggle: The 1968 Olympics and the Making of the Black. Athlete. Minneapolis: University of Minnesota Press.

Bellos, A. (2003). 'The President wins the Midfield Battle'. New Statesman. 3 November: 32-34.

Fraser, N. (2009) 'Feminism Co-Opted'. New Left Review. March/April 56:97-118. Hampson, T and Olchawski, J. (2009). Is Equality Fair. London: Fabian Society. James, C.L.R. (1963). Beyond a Boundary. London: Stanley Paul.

Jarvie, G. (2006). Sport, Culture and Society. London: Routledge. 
Katwala, S. (2004). 'Political Footballs'. Fabian Review: The Age of Terror? 116 (2): 14-16.

Markovits, B. (2003). 'The Colours of Sport'. New Left Review. July/August 22: 151-160.

Obama. B (2009). The Audacity of Hope. New York: Three Rivers Press.

Sen, A. (2009). The Idea of Justice. London: Allen Lane.

Sportscotland (2010) 'A Ten Year Analysis of Spprts Participation data' Edinburgh: Sportscotland.

Wright, E.O. (2009). 'Class Patternings' New Left Review. November/December. 60:101-118.

UK Sport (2009) 'Is UK Sport Equal'. London. UK Sport

Grant JARVIE is currently Vice-Principal and Professor at the University of Stirling. $\mathrm{He}$ is currently advisor to governments on both higher education and sports policy. He was awarded an Honorary Doctorate in 2009 in recognition for his efforts to forge international co-operation and academic developments between Universities. He is an Honorary Professor of the University of Warsaw. He has held established Chairs and been Head of departments and research centres in different UK Universities including, Stirling, Warwick and Heriot-Watt. His research has covered aspects of sport, health and education in other countries including Denmark, China, South Africa, Kenya, Taiwan and France. E-mail address: grant.jarvie@stir.ac.uk 
